\title{
CORRECTION
}

View Article Online

View Journal | View Issue

D) Check for updates

Cite this: J. Mater. Chem. B, 2017, 5, 4797

DOI: $10.1039 / \mathrm{cttb} 90076 \mathrm{~g}$

rsc.li/materials-b

\section{Correction: A spiropyran-coumarin platform: an environment sensitive photoresponsive drug delivery system for efficient cancer therapy}

\author{
Shrabani Barman, ${ }^{a}$ Joyjyoti Das, ${ }^{\mathrm{b}}$ Sandipan Biswas, ${ }^{\mathrm{a}}$ T. K. Maiti ${ }^{\mathrm{b}}$ and \\ N. D. Pradeep Singh (iD *a
}

Correction for 'A spiropyran-coumarin platform: an environment sensitive photoresponsive drug delivery system for efficient cancer therapy' by Shrabani Barman et al., J. Mater. Chem. B, 2017, DOI: 10.1039/ c7tb00379j.

The authors regret that there were errors in Scheme 1, Fig. 2, Scheme 3 and the graphical abstract image. Please see below for the corrected versions of these images (note that the captions are unchanged).

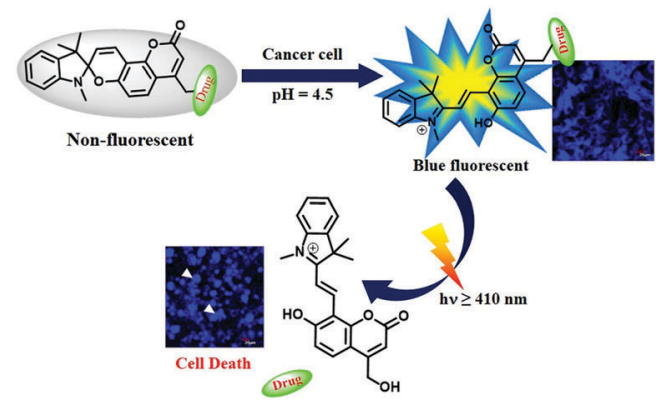

Graphical abstract

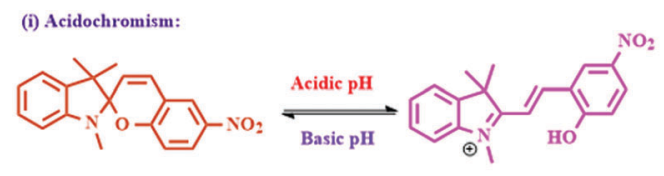

(ii) Photoresponsive Drug Delivery:

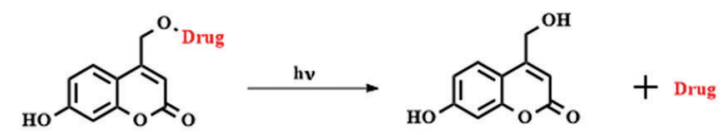

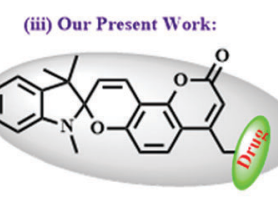

Non-fluorescent

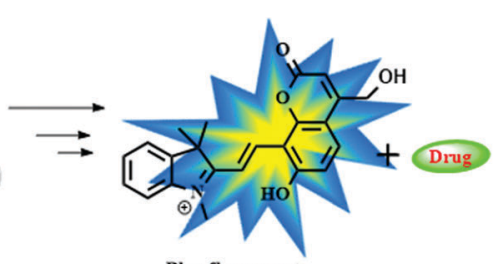

Blue fluorescent

Scheme 1

\footnotetext{
${ }^{a}$ Department of Chemistry, Indian Institute of Technology, Kharagpur 721302, West Bengal, India. E-mail: ndpradeep@chem.iitkgp.ernet.in

${ }^{b}$ Department of Biotechnology, Indian Institute of Technology, Kharagpur 721302, West Bengal, India
} 


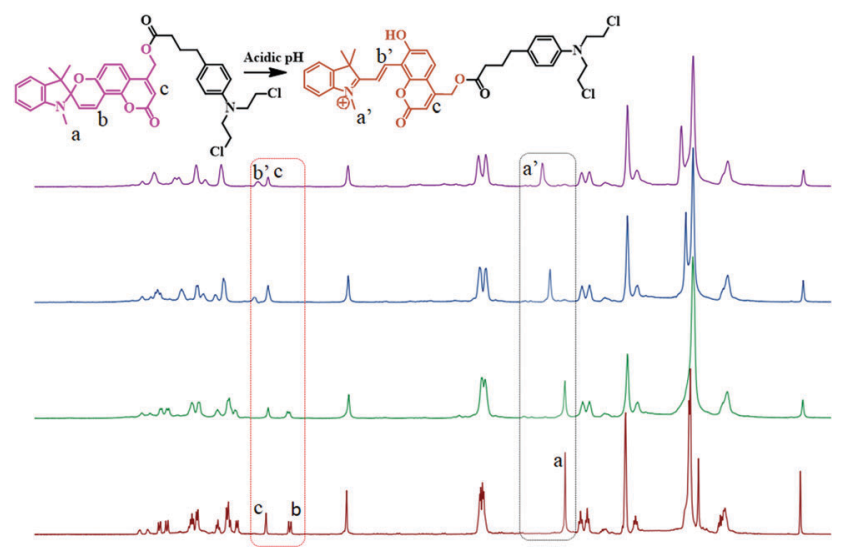

Fig. 2
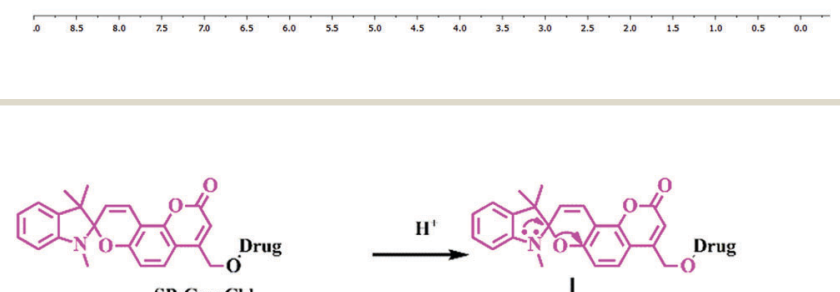

SP-Cou-Cbl
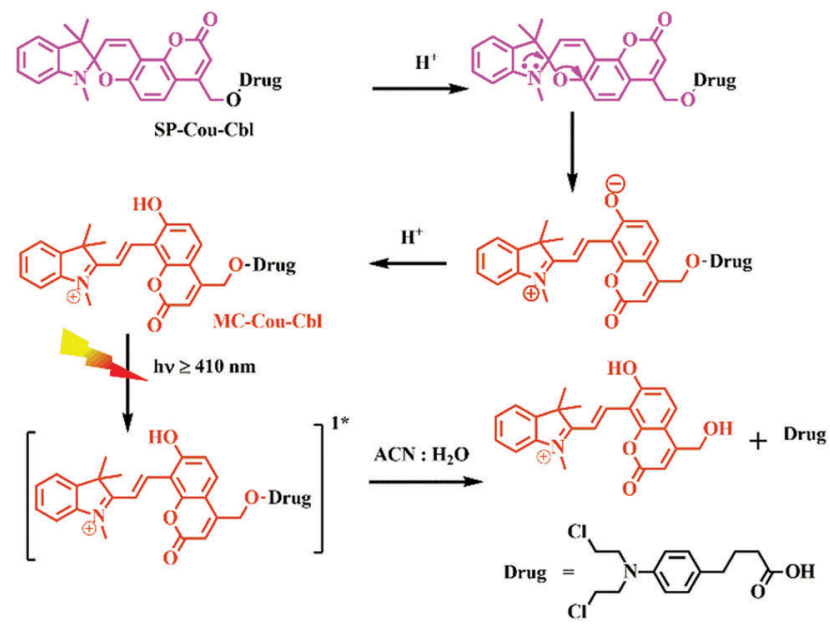

Scheme 3

The Royal Society of Chemistry apologises for these errors and any consequent inconvenience to authors and readers. 